\title{
Tuberculous lymphadenitis associated with human immunodeficiency virus (HIV) in Uganda
}

\author{
A NAMBUYA,* N SEWANKAMBO,* J MUGERWA, ${ }^{*}$ R GOODGAME, ${ }^{*}$ S LUCAS $\dagger$ \\ From the *Departments of Medicine and Pathology, Makarere University School of Medicine, Kampala, \\ Uganda and the $†$ Wolfson Tropical Pathology Department, London School of Hygiene and Tropical Medicine
}

SUMMARY Sixteen adults presented with lymphadenopathy which was tuberculous on biopsy; they were all seropositive for human immunodeficiency virus (HIV-1), but none had the clinical criteria of the acquired immunodeficiency syndrome (AIDS). The biopsy specimen showed caseating tuberculosis, with scanty or no visible acid fast bacilli in seven cases; the remaining nine had a poor cellular reactivity with numerous bacilli. Antituberculous chemotherapy for two months reduced the lymphadenopathy. Two patients subsequently developed AIDS. Mycobacterial cultures were not performed, but the infection was almost certainly Mycobacterium tuberculosis. The space-time clustering of tuberculous lymphadenitis now seen in Kampala, and the unusual non-reactive histopathology, are typical of the impairment of cellular immunity induced by HIV infection.

Those infected with human immunodeficiency virus (HIV) often develop enlarged lymph nodes.' Lymphadenopathy may be caused by a direct effect of the virus (reactive hyperplasia), tumours (Kaposi's sarcoma, lymphoma), or opportunistic infections (such as cryptococcosis). Infection with Mycobacterium tuberculosis is not an infection currently accepted as being among the criteria for the acquired immune deficiency syndrome (AIDS), ${ }^{2}$ but there is an emerging pattern of interaction between HIV and $M$ tuberculosis infection. In Kinshasa $33 \%$ of patients in the tuberculosis wards with confirmed pulmonary tuberculosis were infected with HIV $-1 .{ }^{3}$ HIV infection also predisposes to less common forms of tuberculosis such as tuberculous lymphadenitis. ${ }^{45}$ Tuberculous lymphadenitis used to be uncommon in Uganda. We describe a group of patients seen over a short period who had tuberculous lymphadenitis and were infected with HIV.

\section{Patients and methods}

Over six weeks in 1986, adult patients who presented to the Mulago Hospital, Kampala, with lymphadenopathy were studied. They were examined for clinical features of AIDS. Blood was taken for HIV-1 serology and determined by the Wellcome competitive

Accepted for publication 14 July 1987
ELISA test. A chest $x$-ray picture was taken in most cases. Cervical lymph node biopsy was performed: haematoxylin and eosin and Ziehl-Neelsen stains were prepared, but lymph node culture for mycobacteria could not be done.

Only the cases of tuberculosis were included for analysis. The tuberculous nodes were classified into four groups based on cellular reactivity and numbers of acid fast bacilli:

(A) Reactive $2+$ caseating tuberculosis with large areas of necrosis, focal tubercles of epithelioid cells, and Langhan's giant cells; acid fast bacilli absent or less than one per 100 high power fields at a magnification of 400 .

(B) Reactive 1+ similar to group A, but fewer single tubercles and fewer epithelioid cells and Langhan's giant cells around the necrotic zones; acid fast bacilli one per 10-100 high power fields.

(C) Hyporeactive necrosis with some surrounding epithelioid cells but no giant cells; acid fast bacilli one to 10 per high power field.

(D) Non-reactive (anergic) ${ }^{6}$ areas of necrosis with much nuclear debris and no surrounding epithelioid cells or giant cells; the peripheral macrophages have rounded contours and often clear cytoplasm; acid fast bacilli abundant, more than 10 per high power field.

Each tuberculous patient was treated in hospital with a standard antituberculous three drug regimen (streptomycin, isoniazid, thiacetazone) for two months. 
Table Clinical and histopathological features of 16 patients with tuberculous lymphadenopathy

\begin{tabular}{|c|c|c|c|c|c|c|c|c|c|}
\hline $\begin{array}{l}\text { Case } \\
\text { No }\end{array}$ & $\begin{array}{l}\text { Diarr- } \\
\text { hoea }\end{array}$ & $\begin{array}{l}\text { Hepato- } \\
\text { megaly }\end{array}$ & $\begin{array}{l}\text { Spleno- } \\
\text { megaly }\end{array}$ & $\begin{array}{l}\text { Pleural } \\
\text { effusion }\end{array}$ & Cough & $\begin{array}{l}\text { Skin } \\
\text { rash }\end{array}$ & Nodes & Histology & $A I D S^{*}$ \\
\hline 1 & - & + & - & - & + & - & Axillary, cervical & Non-reactive & + \\
\hline 2 & - & - & - & - & - & - & Cervical & Hyporeactive & - \\
\hline 3 & + & + & + & + & + & - & Axillary, cervical & Hyporeactive & - \\
\hline 4 & + & + & + & - & + & + & Cervical & Hyporeactive & - \\
\hline 5 & - & - & - & - & - & - & $\begin{array}{l}\text { Generalised lymph- } \\
\text { adenopathy }\end{array}$ & Reactive $1+$ & - \\
\hline 6 & - & - & - & - & - & - & $\begin{array}{l}\text { Generalised lymph- } \\
\text { adenopathy }\end{array}$ & Hyporeactive & - \\
\hline 7 & - & - & - & - & + & + & Axillary, cervical & Non-reactive & - \\
\hline 8 & - & - & + & - & - & - & Axillary, cervical & Reactive $2+$ & - \\
\hline 9 & - & - & - & + & + & - & Cervical & Reactive 1+ & - \\
\hline 10 & + & - & - & + & + & - & Cervical & Non-reactive & - \\
\hline 11 & - & - & - & - & - & - & Cervical & Reactive $1+$ & - \\
\hline 12 & - & - & - & - & - & + & Axillary, cervical & Reactive 1+ & - \\
\hline 13 & + & + & - & - & + & - & Axillary, cervical & Reactive 2+ & - \\
\hline 14 & + & - & - & - & + & - & Cervical & Hyporeactive & + \\
\hline 15 & - & - & - & - & + & + & Axillary, cervical & Hyporeactive & - \\
\hline 16 & - & - & - & - & + & - & Axillary, cervical & Reactive 2+ & - \\
\hline
\end{tabular}

*Subsequent development of criteria for AIDS.

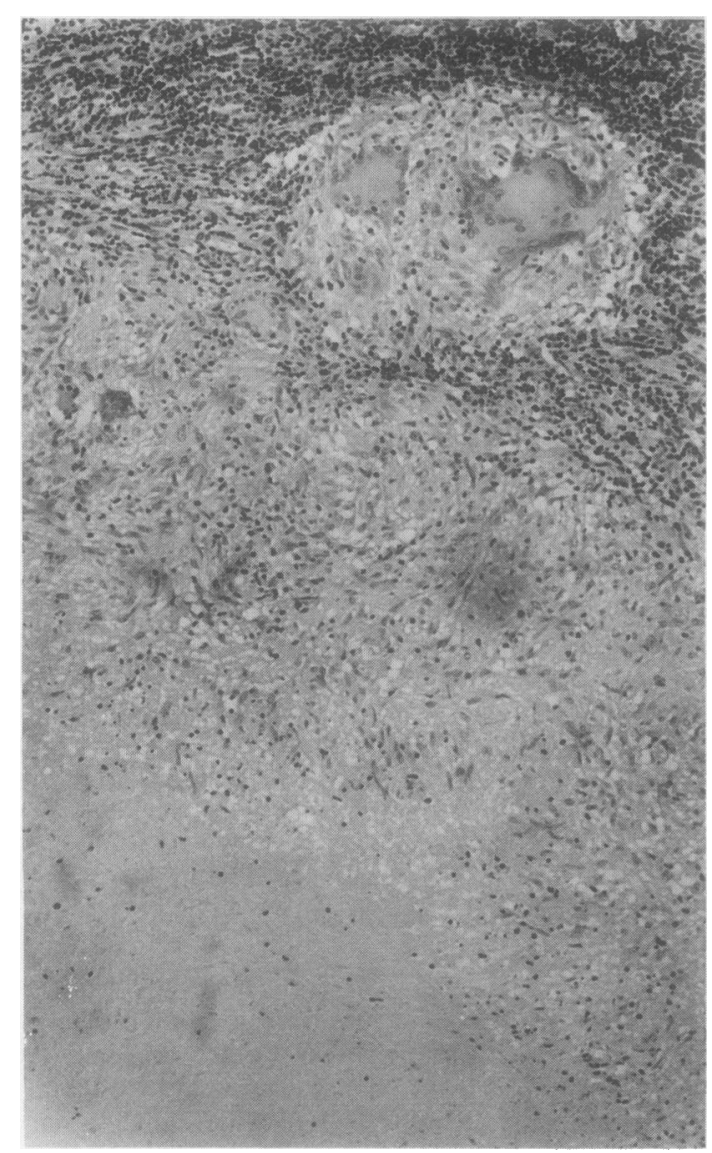

Fig 1 Reactive $2+$ tuberculous lymphadenitis. Single nonnecrotic tuberculoid granuloma and fused granulomas with caseation. Langhans' giant cells present. No acid-fast bacilli seen. (Haematoxylin and eosin.)

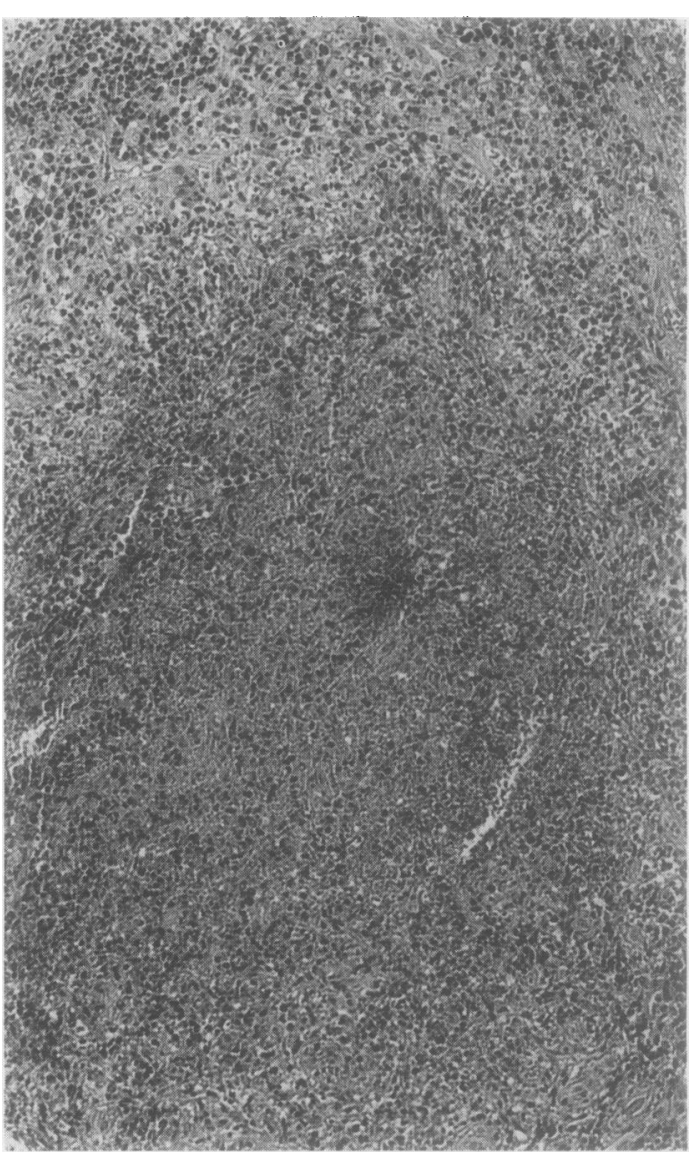

Fig 2 Non-reactive tuberculous lymphadenitis. Non-caseous necrosis with much nuclear debris. No giant cells present. (Haematoxylin and eosin.) 


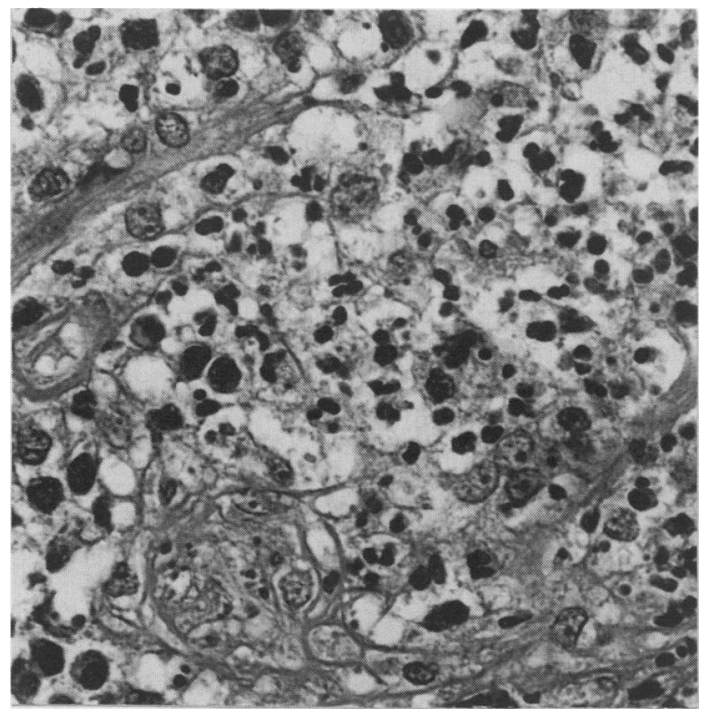

Fig 3 Non-reactive tuberculous lymphadenitis (same case as fig 2). Macrophages with clear cytoplasm and nuclear debris around foci of necrosis. (Haematoxylin and eosin.)

\section{Results}

Sixteen patients with tuberculous lymphadenopathy were identified. Seven were males; mean age was 28 years (range 13-42). Five came from Kampala, the rest from south and west Uganda. All patients were seropositive for HIV-1.

All the patients presented with fever, weight loss, and painful lymphadenopathy. The table shows the distribution of the lymphadenopathy and other clinical features. Symptoms had been present for several months. The skin rash noted in four patients was the pruritic maculopapular eruption characteristic of the African variety of AIDS.

Chest $x$-ray pictures were available for 11 patients: five were normal; three showed hilar lymphadenopathy alone; and three showed pleural effusion with focal parenchymal infiltration (table). None showed apical infiltrates, cavitation, or fibrosis - that is, where pulmonary tuberculosis was apparent it presented a "primary" rather than a "post-primary" pattern.

The histopathological results of the 16 lymph nodes are given in the table: the striking feature was the nine cases of poorly reactive patterns with multiple bacilli (figs 1-4).

Over the two months of chemotherapy two patients developed the World Health Organisation/Centers for Disease Control clinical criteria for AIDS. All the patients responded to antituberculous chemotherapy. In 14, the nodes became impalpable, and in the remaining two, they became pea-sized. Further clinical follow up is not available for these patients.

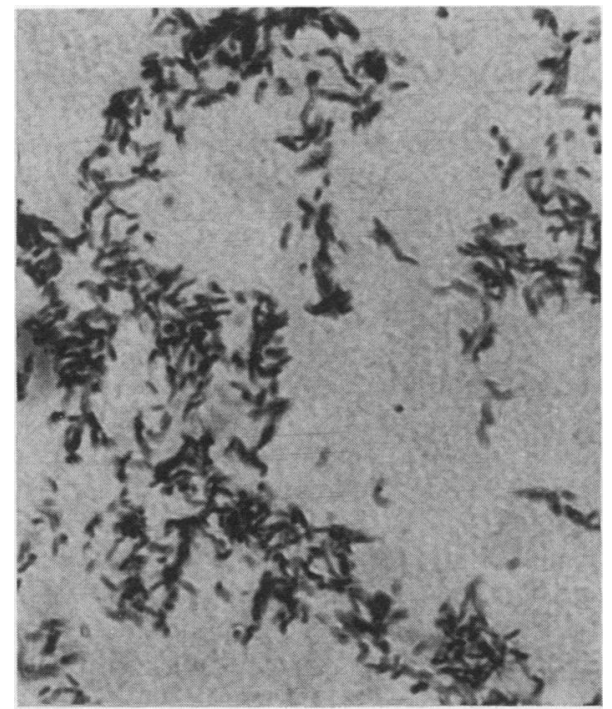

Fig 4 Non-reactive tuberculous lymphadenitis (same case as fig 2). Extra-cellular acid fast bacilli in necrotic foci. (ZiehlNeelsen.)

\section{Discussion}

Histological examination showed that these patients had tuberculous lymphadenitis. We were unable to culture the specimens to prove that the organisms were Mycobacterium tuberculosis, and as yet there are no documented cases of tuberculous lymphadenitis associated with HIV infection in Africa which have been confirmed by culture. We are confident, however, that $M$ tuberculosis is indeed the pathogen. In the era before AIDS in Kenya all cultured cases of tuberculous lymphadenitis were $M$ tuberculosis. ${ }^{7}$

Although non-tuberculous mycobacteria are abundant in Africa, ${ }^{8}$ documented cases of human infection (apart from $M$ ulcerans and $M$ leprae infections) are exceedingly rare. The tuberculosis reference laboratories in east and central Africa report only occasional instances of non-tuberculous mycobacteria in human isolates. Again from Kenya in the 1960's, only $0.54 \%$ of pulmonary isolates were non-tuberculous ( $M$ kansasii and scotochromogens). ${ }^{9}$ In 1985 less than $0.3 \%$ of isolates of human isolates in Zambia were non-tuberculous and these were not considered to be pathogens (J Clancey, personal communication).

The rapid response to chemotherapy in all 16 patients was consistent with tuberculous infection, but unlike that of non-tuberculous infections (such as $M$ avium-intracellulare) in HIV infections.

The histopathology of the group $\mathrm{A}$ and $\mathrm{B}$ reactive patterns was typical for $M$ tuberculosis, but it was also typical of many cases of mycobacterial cervical lymphadenitis outside Africa, such as $M$ avium- 
intracellulare, $M$ kansasii, and $M$ scrofulaceum-and was thus non-specific. The non-reactive necrotic and multibacillary pattern, however, is usually seen in $M$ tuberculosis infection, and only rarely in non-tuberculous mycobacterial infections such as $M$ kansasii, $M$ scrofulaceum, and $M$ xenopi; it is not seen in $M$ aviumintracellulare infections. ${ }^{10}$ In future, we recommend that cultures be done on tuberculous tissues from African patients infected with HIV to confirm our assumption.

In 1983 Masaba studied all the adult tuberculous patients at Mulago Hospital for six months (J Masaba, unpublished observations). Of the 120 patients with tuberculosis, only six presented with tuberculous lymphadenitis. The 16 patients described in this report were seen over six weeks in 1986. Tuberculous lymphadenitis is now a common diagnosis at Mulago Hospital. The fact that every one of the patients in this series showed serological evidence of HIV infection probably explains the recent increase in patients with tuberculous lymphadenitis. In $198616 \%$ of adult blood donors in Kampala were seropositive for HIV1."

HIV infection is pathogenetically important in adult tuberculosis in Uganda. The histological findings suggest an abnormal immune response. Although some of the patients showed a typical reactive pattern, one would not expect to find such a striking clustering of hyporeactive and non-reactive responses in patients without some underlying cell mediated immune defect. Furthermore, in a recent review of necropsies on 22 adult Ugandans dying of AIDS in Mulago Hospital between $1983-6,{ }^{12}$ four had widely disseminated tuberculosis in addition to other infections including cytomegalovirus, progressive multifocal leucoencephalopathy, toxoplasmosis, cryptococcosis and candidiasis. In all these four cases the histology showed hyporeactive or non-reactive patterns with numerous bacilli. From the findings of the present study and the aforementioned, tuberculous lymphadenitis may develop during HIV infection with a spectrum of pathology ranging from typical reactive type to the anergic non-reactive type; but by the time of death (caused by tuberculosis and other infections), the immunodeficient pattern is found.

Tuberculosis often precedes a diagnosis of AIDS in patients infected with HIV in the United States, ${ }^{4}$ suggesting that it is a more virulent disease than the standard infections, currently the criteria for AIDS, and that it emerges earlier during the course of diminishing cell mediated immunity from HIV infection. In Africa where $M$ tuberculosis infection is very common it is impossible to define accurately whether this HIV associated tuberculosis is a primary, a latent reactivated, or a secondary infection. Morbid anatomy alone cannot solve that problem. Studies on Haitian immigrants in the United States have shown that the clinical manifestations of tuberculosis are different in patients with AIDS compared with those without. ${ }^{5}$ The AIDS groups had less pulmonary disease and more disseminated and lymphatic tuberculosis, consistent with our findings in Uganda.

We conclude that HIV infection contributes to the changing pattern of tuberculosis in Mulago Hospital. The ability of HIV infection to change the biology of tuberculosis has important implications for public health and for clinicians taking care of patients in 8 environments where both HIV and tuberculous infec- $\nexists$ tions are common.

\section{References}

1 Fauci AS, Masur H, Gelman EP, Markham PD, Hahn BH, Lane HC. The acquired immunodeficiency syndrome: an update. Ann Intern Med 1985;102:800-13.

2 World Health Organisation Center for Disease Control. Acquired immunodeficiency syndrome (AIDS). WHO/CDC case definition for AIDS. Weekly Epidemiological Record 1986;61:69-73. Ф

3 Mann J, Snider DE, Francis H, et al. Association between HTLVIII and tuberculosis in Zaire. JAMA 1986;256:346.

4 Duncanson FP, Hewlett D, Maayan S, et al. Mycobacterium tuberculosis infection in the acquired immunodeficiency syndrome. A review of 14 patients. Tubercle 1986;67:295-302.

5 Pitchenik AE, Cole C, Russell BW, Fischl MA, Spira TJ, Snider $\frac{\bigcirc}{\mathbb{D}}$ DE. Tuberculosis, atypical mycobacteriosis and the acquired immunodeficiency syndrome among Haitian and non-Haitian $\overline{\bar{O}}$ patients in South Florida. Ann Intern Med 1984;101:641-5.

6 O'Brien JR. Non-reactive tuberculosis. J Clin Pathol 1954;7: 216-25.

7 Sula L, Stott H, Rubin M, Kiaer J. A study of mycobacteria isolated from cervical lymph glands of African patients in Kenya. Bull WHO 1960;23:613-34.

8 Shield MJ, Stanford JL, Paul RC, Carswell JW. Multiple skin testing of tuberculosis patients with a range of new tuberculins, 3 and comparison with leprosy and $\mathbf{M}$ ulcerans infection. $J \boldsymbol{H y g}$ ? 1977;77:331-48.

9 East African/British Medical Research Council Kenya Tuber- $\supsetneq$ culosis Survey. Tubercle 1968;49:136-56.

10 Lucas S. Mycobacteria and the tissues of man. In: Ratledge C, Stanford JL, Grange JM, eds. The biology of the mycobacteria. $\frac{1}{O}$ Vol 3. London: Academic Press, 1987 (in press).

11 Carswell JW. AIDS in Uganda-a review. Health Information $\mathrm{N}$ Quarterly 1986;2:22-43.

12 Lucas S, Wamukota W. HIV and the local African population. In: N Pounder RE, Chiodini P, eds. Advanced medicine 23. UK. ㄱ London: Ballière Tindall, 1987:102-11

Request for reprints to: Dr S Lucas, Department of Histopathology, UCL School of Medicine, University Street, $\stackrel{\circ}{\stackrel{C}{\varrho}}$ London WCIE 6JJ, England. 